Int. J. Electrochem. Sci., 15 (2020) $8732-8742$

\title{
Enhanced Electrochemical Properties of Titanium Doped Lithium Manganese Oxide with Nanorod-like Morphology
}

\author{
Jing Xue* , Hu Zhang, Tuoying Yang, Xiuxing Zhang \\ Shaanxi X-ray Detection and Application Research and Development Center, School of Physics and \\ Electrical Engineering, Weinan Normal University, Weinan 714099, China \\ *E-mail: xuejingwnu@126.com
}

doi: $10.20964 / 2020.09 .61$

Received: 10 May 2020 / Accepted: 13 July 2020 / Published: 10 August 2020

The Ti-doped $\mathrm{LiMn}_{2} \mathrm{O}_{4}\left(\mathrm{LiMn}_{1.97} \mathrm{Ti}_{0.03} \mathrm{O}_{4}\right)$ nanorods are prepared by self-sacrificial template method with titanium dioxide $\left(\mathrm{TiO}_{2}\right)$ nanoparticles and manganese hydroxide $(\gamma-\mathrm{MnOOH})$ nanorods as doping agent and manganese precursor, respectively. The obtained $\mathrm{LiMn}_{1.97} \mathrm{Ti}_{0.03} \mathrm{O}_{4}$ nanorods possess obvious nanorod structure and no other impurity peaks can be observed in the XRD pattern of the titanium doped sample, which suggests the successful inheritance of nanorod structure of $\gamma-\mathrm{MnOOH}$ in the $\mathrm{LiMn}_{1.97} \mathrm{Ti}_{0.03} \mathrm{O}_{4}$ sample with high purity. According to the electrochemical results, the $\mathrm{LiMn}_{1.97} \mathrm{Ti}_{0.03} \mathrm{O}_{4}$ nanorods present excellent cycling performance. When tested at $0.5 \mathrm{C}$, the $\mathrm{LiMn}_{1.97} \mathrm{Ti}_{0.03} \mathrm{O}_{4}$ nanorods show an initial discharge capacity of $125.1 \mathrm{mAh} \mathrm{g}^{-1}$ with high capacity retention of $93.8 \%$ after 100 cycles. Moreover, the $\mathrm{LiMn}_{1.97} \mathrm{Ti}_{0.03} \mathrm{O}_{4}$ nanorods show better rate performance and cycling stability under high temperature. This work indicates that the co-modification of Ti-doping and nanorod morphology has synergistic effect, which can effectively help enhance the electrochemical properties of $\mathrm{LiMn}_{2} \mathrm{O}_{4}$.

Keywords: Lithium manganese oxide; Ti-doping; Nanorod-like morphology; Synergistic effect; Cycling stability

\section{FULL TEXT}

(C) 2020 The Authors. Published by ESG (www.electrochemsci.org). This article is an open access article distributed under the terms and conditions of the Creative Commons Attribution license (http://creativecommons.org/licenses/by/4.0/). 